\title{
CONTEXTUAL RESOURCES FOR INFERRING UNEXPRESSED REFERENTS IN JAPANESE CONVERSATION ${ }^{1}$
}

\author{
Tomoyo Takagi
}

\begin{abstract}
The phenomenon of "elliptical" expressions in Japanese has been extensively studied in the field of Japanese linguistics. However, this phenomenon has been often treated as a general syntactic feature of Japanese, and the question of how this feature is realized in actual use of the language has been rather neglected. The present paper is intended to analyze how speakers of Japanese actually deal with the task of interpreting unexpressed elements that emerge in their talk in interaction. Using video- and audio-data of naturally occurring conversations in Japanese, it is shown that, in producing and understanding utterances involving unexpressed referents, conversational parties utilize not only their morphological and syntactic knowledge but also various, multilayered resources that are available to them in the immediate context of interaction.
\end{abstract}

Keywords: Japanese conversation, Ellipsis, Zero anaphora, Contextual resources, Interaction.

\section{Introduction}

The phenomenon of 'elliptical' expressions in Japanese has been a popular subject in the field of Japanese linguistics. In formal linguistic studies unexpressed elements in sentences have been referred to as null/zero anaphora and thought to be represented in abstract syntactic structures but not phonetically realized. In these studies attempts have been made at accounting for (un)grammaticality of certain (usually constructed) elliptical sentences in terms of syntactic structure rules, although the interpretation of null/zero anaphora (i.e. how the hearer interprets the unexpressed element) has been left outside of the scope of the field. In the field of pragmatics and discourse-oriented studies, referential choice between ellipsis and overt reference has been explained in terms of cognitive constraints or pragmatic principles (Hinds 1982; Clancy 1980; Okamoto 1985). Studies of referential choice in conversation such as Lee (1989) and Clancy (1996a, 1996b) have taken important steps in investigation of grammar in that they described actual use of elliptical expressions

\footnotetext{
${ }^{1}$ I wish to thank Pat Clancy, Jack Du Bois, Makoto Hayashi, Yoshi Ono, Sandy Thompson and the anonymous reviewer of this journal for reading earlier versions of this paper and making a number of valuable comments. I am, of course, alone responsible for any mistakes and omissions that remain in the paper. I am also thankful for the transcribers of Pacific Rim Corpus at the University of California at Santa Barbara, from which most of the data in this study are taken.
} 
in real-life everyday conversation. However, at least to my knowledge, little work has been done on how speakers of Japanese actually deal with the task of interpreting unexpressed elements in their talk in interaction as it unfolds moment-by-moment.

In this study, based on observations of ordinary Japanese conversation, which is the most predominant speech event through which everyday interaction is realized, I will investigate what sorts of verbal or non-verbal resources can be employed to determine the interpretation of unexpressed elements. In other words, I will explore what is actually happening in the domain that has been rather neglected as having few describable/generalizable regularities of its own: Particular situations in which a language is being used. Underlying this approach is the assumption that although interpreting and producing 'elliptical' utterances in appropriate ways are indeed a reflection of the nature of language use, speakers' knowledge of lexicon and syntax cannot be realized as it is in language use in everyday life without interacting with the situated and particularized context. Japanese speakers must have knowledge of what argument structures are possible for each verb, which of them are more frequently used, and what grammatical morphemes pertain to argument structure in what ways, in order to be able to interpret and produce appropriately utterances with relevant participants unexpressed. ${ }^{2}$ However, determination of which of the possible argument structures is at work at the particular moment of an occurrence of a verb and what are the exact referents of the projected participants ${ }^{3}$ is also informed by non-syntactic cues such as discourse features and other contextual resources. The main purpose of this study is to describe how discourse/contextual as well as morphosyntactic resources are used to identify referents of participants projected as relevant by the use of a predicate in a particular context. ${ }^{4}$ I hope then this study will provide a piece of evidence that use/interpretation of elliptical expressions is made possible by the very fact that they are situated in and informed by actual interactional environments, which constitute empirically describable orderliness.

In the following we will first look at the most basic patterns of tracking of referents

\footnotetext{
${ }^{2}$ For detailed discussion of this theoretical framework, see Clancy (in preparation). For a different view of argument structure in Japanese, see Ono and Thompson (1997).

${ }^{3}$ In order to distinguish animate or inanimate entities potentially involved in an action or state represented by a predicate from interactants in conversations, I refer to the former as 'participants' and to the latter as (conversational) 'parties.' Goldberg (1995) distinguishes participant roles, which are associated with verbs' frame semantics, from argument roles, which are associated with constructions and roughly correspond to Fillmore's early case roles. However, although I realize that this distinction can be theoretically significant in many ways, in most of the present discussion, the terms 'participant' and 'argument' can be used interchangeably without affecting the gist of the analyses. In this paper I will mainly use the term 'participant' according to the following reasoning: 1) argument roles emerge as a result of abstraction from the recurrence of each verb in a set of constructions; 2) in situations of real language use, which are always realized in particular ways, it is probably more likely that Japanese speakers understand utterances with unexpressed elements in terms of particular conceptual roles or specific referents rather than (abstract) argument roles; 3) it then makes more sense to use the term 'participant' in the present study, which emphasizes the significance of Japanese speakers' ability to utilize various contextual resources at the moment of interaction in dealing with unexpressed elements.

${ }^{4}$ As we will see below, processes of inferring referents are multilayered, complex and diverse. By providing excerpts under a certain heading I do not mean at all that the feature discussed under the heading is the only resource that the parties to the interaction employed in inferring the referents in that particular occasion.
} 
of unexpressed participants in the same argument across multiple turns. We will then look at cases of switch reference, where various types of resources are called for to signal the shift in reference. Note that these resources are not syntactically obligatory markers that indicate that the subject of the subsequent clause is shifted, which have been documented in other language families. Nevertheless, they seem to be regularly correlated with the occurrence of switch reference, and thereby, to project the switch reference or retroactively confirm that the subject will be/was shifted to another referent. They are useful resources that help the hearers keep track of which of the possible referents is the referent of the implicit subject of the predicate in the current utterance. In section 4 we will examine cases in which contingent features of on-going interactions are invoked in identifying the relevant references. Section 5 deals with a case in which multiple resources employed by the speaker are incongruous. Although this causes confusion on the part of the hearer, she still infers possible participants among which the intended referent is to be clarified through the work of reference negotiation, which provides further evidence for the language users' ability of and orientation to relating their knowledge of lexical properties of verbs to available contextual resources in the most relevant way.

\section{The simplest pattern of tracking referents}

One of the most productive devices that conversational parties can draw on in inferring referents of participants involved in the event described by a predicate is repeated use of the same predicate, often across turns, to which the participants invoked but unexpressed are related in the same way. The following excerpt illustrates the point. The verb mieru 'look' is repeatedly used by the same speaker after several turns and then by another speaker in the subsequent turn.

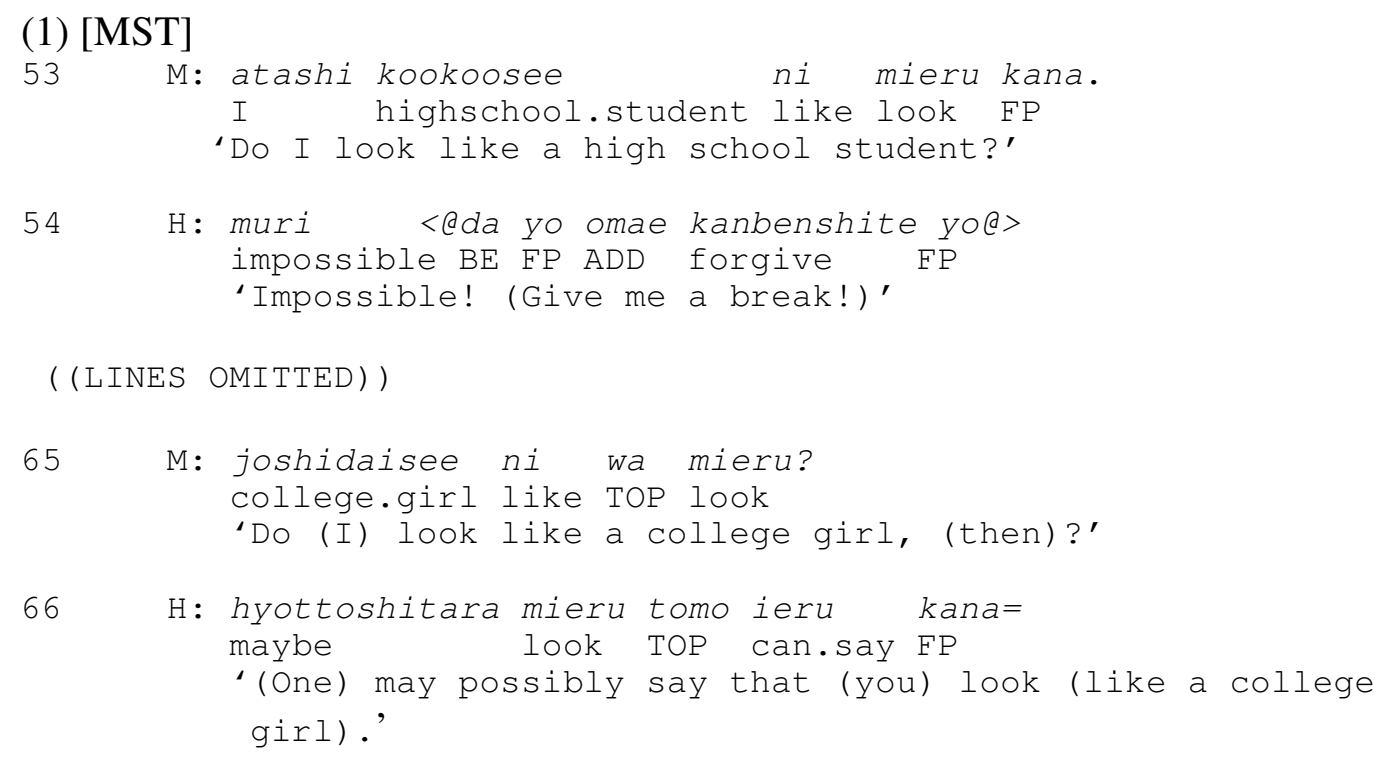

In the talk prior to Excerpt (1) the parties to this conversation are arguing about whether A, 
who does not appear in this excerpt, can look like a high school student or not. At line $53 \mathrm{M}$ refers to herself as atashi 'I' and then continues her turn with the construction -ni mieru 'look like', which was already repeatedly used in the prior talk about A's appearance, followed by a question particle kana. $\mathrm{M}$ is now asking whether the proposition kookoosee ni mieru 'look(s) like a high school student' applies to her. After receiving H's negative response to the question, $\mathrm{M}$ issues another question (indicated by rising intonation) in line 65, again using the same construction but replacing kookoosee 'high school student' with joshidaisee 'college girl.' $\mathrm{H}$ in his response incorporates the verb but not joshidaisee ni. There are a few elements that seem to be involved in constraining the possibility of "who looks like a college girl': 1) the word joshidaisee 'college girl' in line 65 specifies the gender of the one who looks like joshidaisee; 2) M's use of the topic marker wa in line 65 indicates the antecedent part is contrasted with some other notion bearing the same type of relation with the rest of the sentence, which strongly invokes the sentence already produced in line 53 in the same format but with an explicit reference to the speaker and a different item preceding ni mieru; 3 ) a turn that is adjacent to a prior turn is usually assumed to be tied to and responsive to it. Therefore H's turn in line 66 is interpreted by reference to M's turn in line 65. Since the same predicate mieru is used in H's response turn, the most natural interpretation of his utterance would be one based on the same structural frame as is imposed by the use of mieru in M's preceding turn. ${ }^{5}$ This instance shows that once a grammatical relation between an explicit NP and a predicate is established, the referent is tracked as bearing the same grammatical relation with the predicate when it re-appears in the subsequent turns. This seems to be one of the simplest and most basic ways in which conversational parties interpret each other's utterances with unexpressed arguments, and they also formulate their utterances based on this pattern. As casual observation of Japanese conversational data immediately reveals, explicit reference to parties in the ongoing speech event is very rare. One might think that the above excerpt happens to include some tokens of the same predicate in a sequence in which the referent of the subject (i.e. M) is implicit 'by default.' However, the effect of the cohesion created by the same predicate or semantically related predicates is not limited to the case of unexpressed parties in on-going speech events. In the following excerpt, $\mathrm{H}$ and $\mathrm{Y}$ are talking about young people who go to developing countries to serve in community development.

\section{(2) [INSEI]}

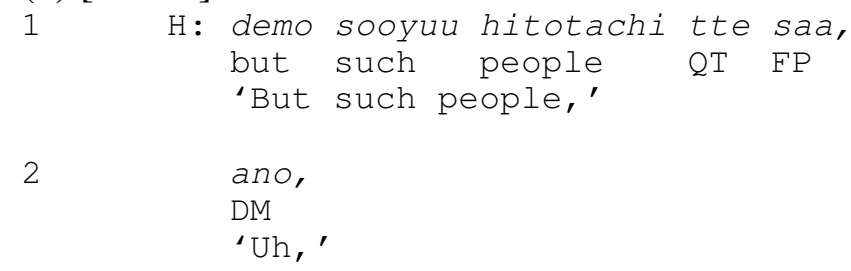

${ }^{5}$ For example, mieru can mean ' $X$ can see $Y$ ' or ' $X$ look(s) like $Y$ ' depending on the context. The adjacency between M's turn and H's turn, which both include mieru, greatly reduces the possibility of the former interpretation: By reference to the way mieru is used in M's turn, the most likely interpretation of the use of mieru in H's turn is the same one as in M's turn. Moreover, given that M's turn is a question making an answer from $\mathrm{H}$ relevant in the next turn, only such an interpretation of mieru allows H's utterance to be understood as an answer to M's question. For concise and useful discussion of conversational interactants' orientation to this tying between adjacent turns, see Levinson (1983) and Heritage (1984). 
sho-

shigoto yametari toka shite ikunto chau no?

job quit TD do:CONT go:NM different $Q$

'quit (their) jobs then go or something, don't (they)?'

Y: $u=n$ soo soo

RT right right

'Yeah, right.'

shigoto yametari,

job quit:CONT

'(They) quit (their) jobs,'

yasundari shite [ikun dakedo.

take.leave:CONT do:CONT go:NM BE.CON

'or take some time off and then go.'

$\mathrm{H}: \quad \begin{gathered}\text { [nee, } \\ \mathrm{RT}\end{gathered}$

soonan ya,

right FP

'Right,'

yasundatoshitemo taitei nanka mukyuu ya te itterukedo=, took.leave:CON mostly TD unpaid FP QT say:PROG:CON

'No salary will be paid while you are on leave, (they) say.'

In H's first turn, who 'quit a job and go (abroad)' is explicitly expressed in line 1 soo yиu hito tachi 'such people,' which refers to a referent already introduced in the prior talk. Y repeats the same predicate as $\mathrm{H}$ used shigoto yametari 'quit a job' and adds another predicate yasundari 'take some time off' without mentioning the doer of such actions. In line $10 \mathrm{H}$ then repeats the predicate that $\mathrm{Y}$ used in the prior turn with no explicit reference of the doer of the action. It is obvious to the conversational parties and to the analyst that the referent mentioned in line 1 is tracked in the subsequent turns and understood as bearing the same grammatical/semantic relation with the repeated predicates, that is, as the doer of the actions expressed by the predicates. Thus cohesion among predicates occurring in sequence provides a clear case of tracking referents of potential participants in the described event and interpreting their relation to the verb in the same way as in the prior occurrence.

The question is how reference tracking is resolved in more complicated situations in which different predicates are used in different types of constructions from one turn to another, which are not uncommon at all. Clancy (1980) observes that ellipsis was used 28 percent of the time in cases of switch reference and that "this 28 percent rate of elliptical switch references in Japanese suggests rather high tolerance for potential ambiguity." She notes that the immediate repetition of the subject of a clause which does not have the same referent as the immediately preceding one, and the use of a postverbal subject serve as compensatory devices to disambiguate elliptical referents. Taking Clancy's observation as a point of departure, in the following sections, we will take up the issue of how switch 
reference itself can be done and actually is done with unexpressed referents, in other words, what sorts of resources conversational parties are provided with to appropriately produce and interpret 'implicit' switch references.

\section{Cases of switch-reference}

\subsection{Voice alternation}

In some cases a certain grammatical operation can participate in projecting an appropriate argument structure for an utterance with unexpressed participants. In the following instance, $\mathrm{H}$ introduces an event in which he was accosted by a young man on the street at midnight.

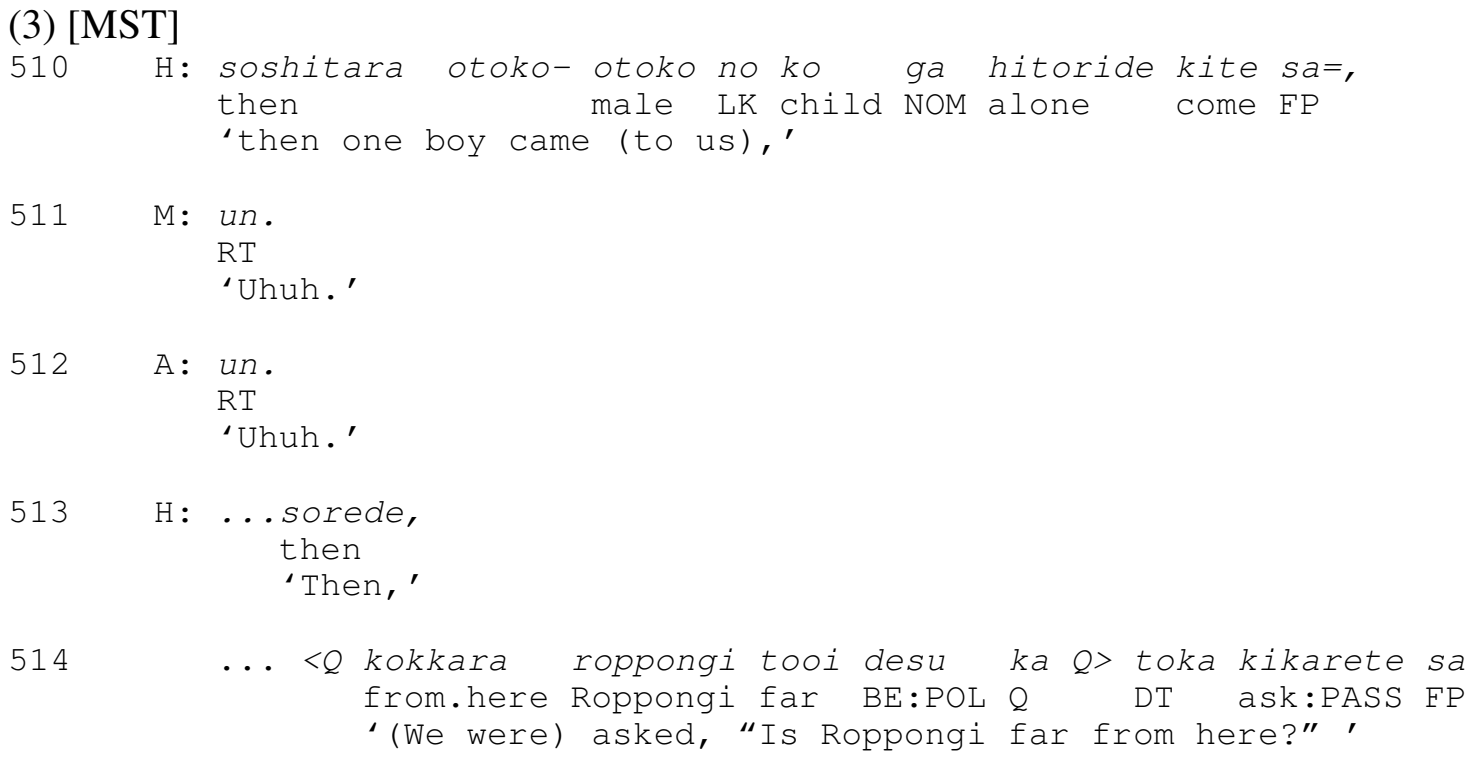

In line 510 the young man is explicitly mentioned as the one who approached the speaker on the night of the incident. In line $514 \mathrm{H}$ uses a different verb, kiku 'ask' in the passive form, which implies at least two potential participants the 'asker' as the referent of the oblique argument and the 'askee' as its subject, although neither is overtly expressed. In this particular context of a story-telling of a past event, the possible participants are speaker $\mathrm{H}$ and the young man who accosted him in the event being told. And the most natural, default interpretation is that the speaker identifies himself with the 'askee', that is, the one who was asked, as supported by Kuno's (1987) theory of empathy. Kuno proposes the following as part of his theory of empathy:

Surface Structure Empathy Hierarchy: It is easier for the speaker to empathize with the referent of the subject than with the referents of other NPs in the sentence.

Speech Act Empathy Hierarchy: The speaker cannot empathize with someone else 
more than with himself.

Thus the 'askee' is unequivocally inferred to be speaker H and the 'asker' is the young man. Importantly, although the number and the nature of potential participants (i.e. the 'asker' and 'askee') in the event and their respective grammatical relations to the predicate are projected by the use of the verb in the passive form, the interpretation of which of the two potential participants has which referent should be based on the preceding context providing the frame of story-telling (i.e. $\mathrm{H}$ as the story-teller and others as story-recipients) and characters in the story (i.e. $\mathrm{H}$ and the strange man) as well as invocation of such pragmatic information as proposed by Kuno. Note also that although the honorific form of the verb has the same form as the passive, the honorific reading is unquestionably excluded from potential interpretations. If it was the honorific form, the potential participant could only be the human being who asked the question, but the referent cannot be the speaker himself because the speaker cannot be the target of the honorific, nor the boy can be the referent because in the context of telling a story about a strange person who accosted the speaker, it is inconceivable to use honorific forms to show deference to the stranger. Thus knowledge of grammar/lexicon regarding a particular form and the capability of producing/interpreting discourse, which includes knowledge of conversational organization as well as cultural norms, interact with each other in allowing the language user to arrive at an appropriate interpretation.

\subsection{Sorede/soshitara alternation}

Another device which seems to indicate subject shift is the clause-combining system. Discussing the two verb suffixing forms -TE and -TARA in Japanese narratives ${ }^{6}$, Iwasaki (1993) proposes that they are distinctively used in terms of continuity of subject across two clauses: TE is basically associated with the continuity of the subject, while TARA with the discontinuity of the subject. The following example illustrates the canonical pattern of the use of these suffixes. (Iwasaki 1993: 63). ${ }^{7}$

(4) (Las Vegas)

128 K: (1.0) soshite hairenakute

and enter:POT:NEG:TE

$129 \mathrm{~K}:$ =okoshite

wake up:TE

\footnotetext{
${ }^{6}$ In the transcripts of my own data, where the -tara form is not the focus of discussion, it is glossed as COND to represent its basic function of marking a conditional.

${ }^{7}$ The following abbreviations and conventions are used in the transcriptions taken from Iwasaki (1993): ACC (accusative); FRG (fragment); INJ (interjection and hesitation); NEG (negative); IT (interactional element); POT (potential); NOM (nominative); SOF (softening word); = (latching); ... (short pause, less than half a second).
} 


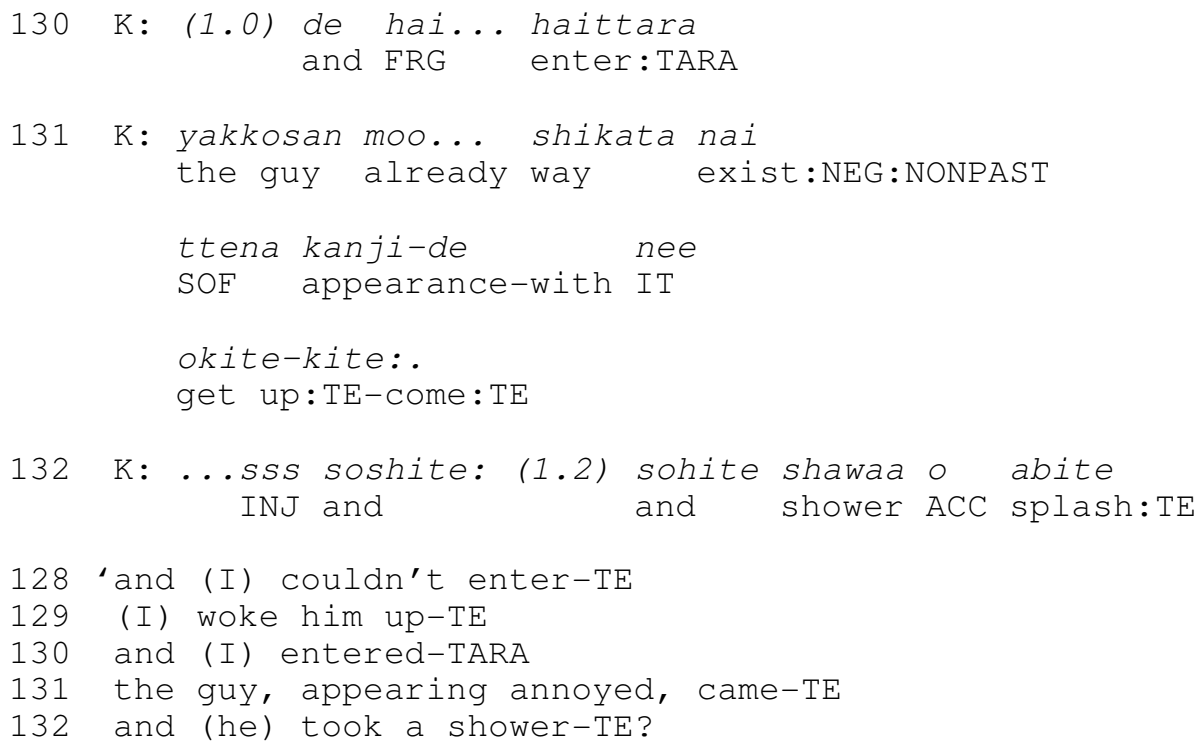

To account for some exceptional cases, Iwasaki (1993) proposes a model of the structure of the speaker's epistemological perspective in which three types of perspectives are placed along a scale of information accessibility: A perspective on SELF or the S-perspective is on the higher side of the scale, a perspective on OTHERS or the O-perspective in the middle, and a perspective which does not involve any autonomous sentient being or ZEROperspective is located on the lower side of the scale. Iwasaki argues that the Japanese switch reference system is in fact more sensitive to speaker's perspective and information accessibility rather than to strict subjecthood and that TARA is also used when there is a slight change from a higher degree of information accessibility to a lower degree of information accessibility within S-perspective (i.e. without switch reference).

A pair of Japanese coordinating conjunctive adverbs sorede and soshitara, both of which can be roughly translated as 'and (then)' in English and usually appear in sentenceinitial position seem to show a similar pattern to that of -TE and -TARA described by Iwasaki (1993). ${ }^{8}$ The following excerpts represent uses of sorede and soshitara congruent with continuous and discontinuous subject marking respectively. The excerpts are taken from a conversation in which $\mathrm{M}$ tells $\mathrm{R}$ how her family learned that her father had stomach cancer.

8 Sorede consists of the demonstrative pronoun sore 'that' and the case particle $d e$, which indicates reason, means, or circumstances, roughly equivalent to 'with' in English. Soshitara is constitutive of the demonstrative adverb soo 'so/thus' and the TARA form of the verb suru 'do', that is, shitara. Another conjunctive adverb soshite, which is derived from sooshite (soo + the TE form of the verb suru 'do' shite) may be considered a better counterpart of soshitara in terms of its morphological structure. However, soshite is mainly used in written texts and is infrequently seen in conversation. Although sorede in spoken texts does not completely take the place of soshite in written texts, in conversation sorede is much more dominant in situations where soshite could be used as well (with somewhat added formality). Thus I consider sorede and soshitara to form an adverbial pair comparable to the suffix pair -TE/-TARA. 


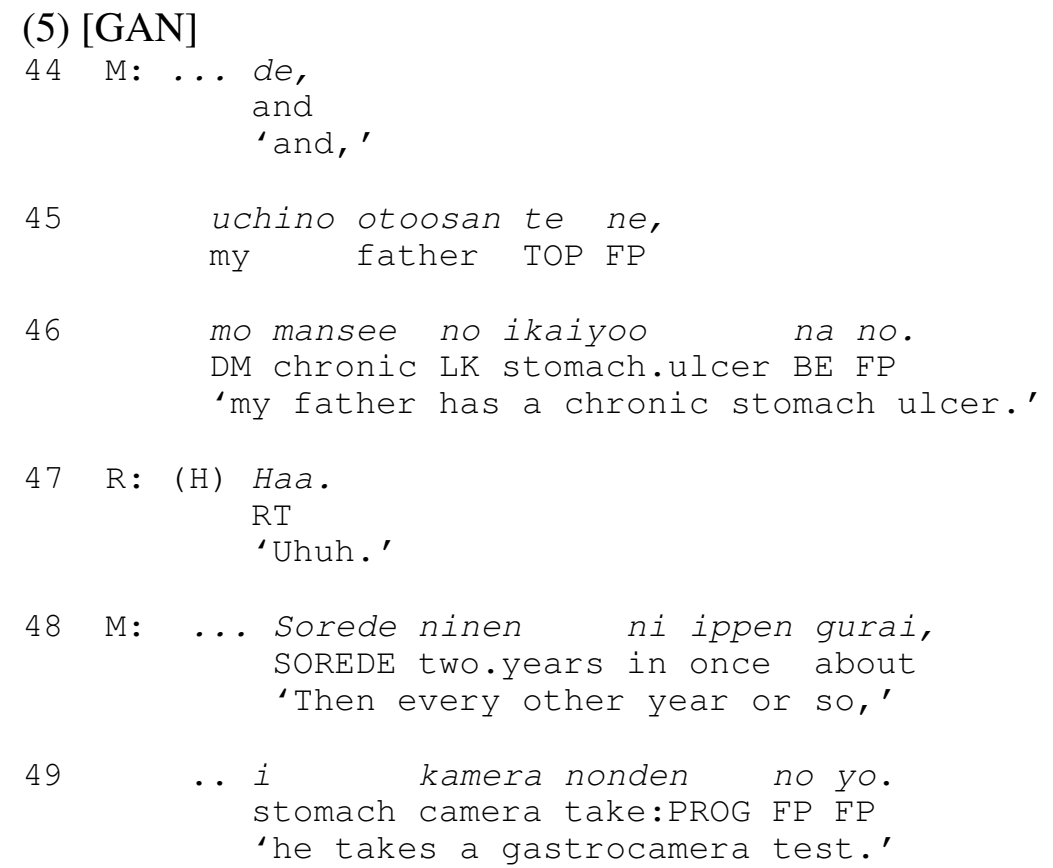

In lines 45 through 46, $\mathrm{M}$ reports that her father has a chronic stomach ulcer. After the recipient's response in line $47, \mathrm{M}$ resumes her turn with sorede and tells about taking a gastrocamera test every other year. Even though the subject referent in line 49 is not expressed, it is clearly the same as that of the predicate in line 46, her father. taken from.

The talk in (6) takes place somewhat later in the same conversation as Excerpt (5) is

(6) $[\mathrm{GAN}]$

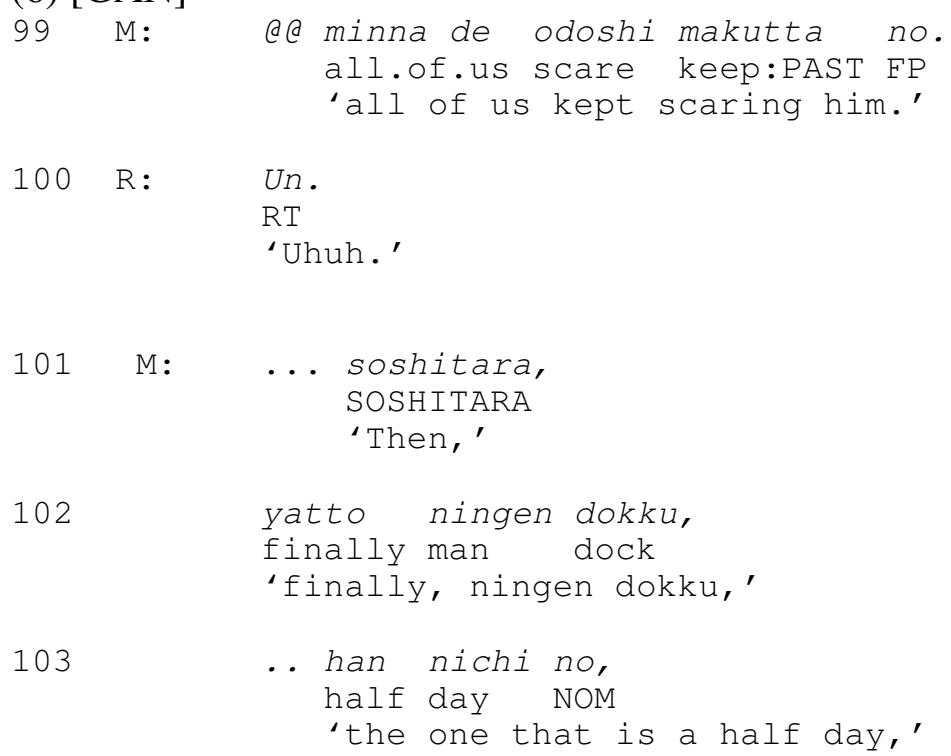




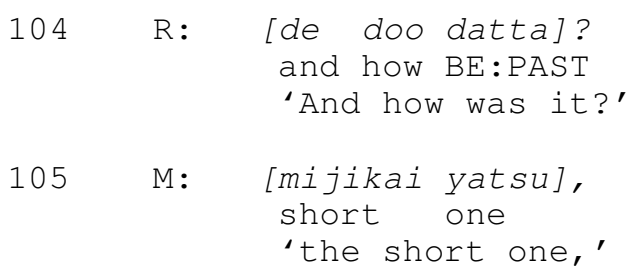

In the preceding part $\mathrm{M}$ tells $\mathrm{R}$ how her family persuaded her father to take a medical examination. In line $99 \mathrm{M}$ summarizes what her family did as minna de odoshi makutta no 'all of us kept scaring him.' After R's recipient token un, M mentions the medical examination commonly known as ningen dokku (lit. man dock). M further specifies what kind of ningen dokku it was, although the latter half of the specification mijikai yatsu 'the one that is quicker' is overlapped by R's somewhat premature question de doo datta? 'then how was it?' It is clear that on hearing the name of the medical examination, R understands that somebody entered the hospital for the medical examination and that it is M's father who entered the hospital. The two parts (line 99 and lines 101 through 103) of M's utterance are connected by soshitara and there is a discontinuity of the subject across them, which is appropriately interpreted by $\mathrm{R} .{ }^{9}$

Iwasaki (1993) also observes that TARA never appears with a third person subject when it is followed by a first person subject clause, whereas TE is occasionally used in such a situation. More generally, the use of TARA is more strictly restricted for the shift of higher-to-lower information accessibility. My data include a few cases in which sorede is used when there is a subject shift from third person subject to first person subject but no instance of soshitara in the same environment, which is also consistent with Iwasaki's finding (see also line 513 in Excerpt (3)).

(7) $[\mathrm{MST}]$

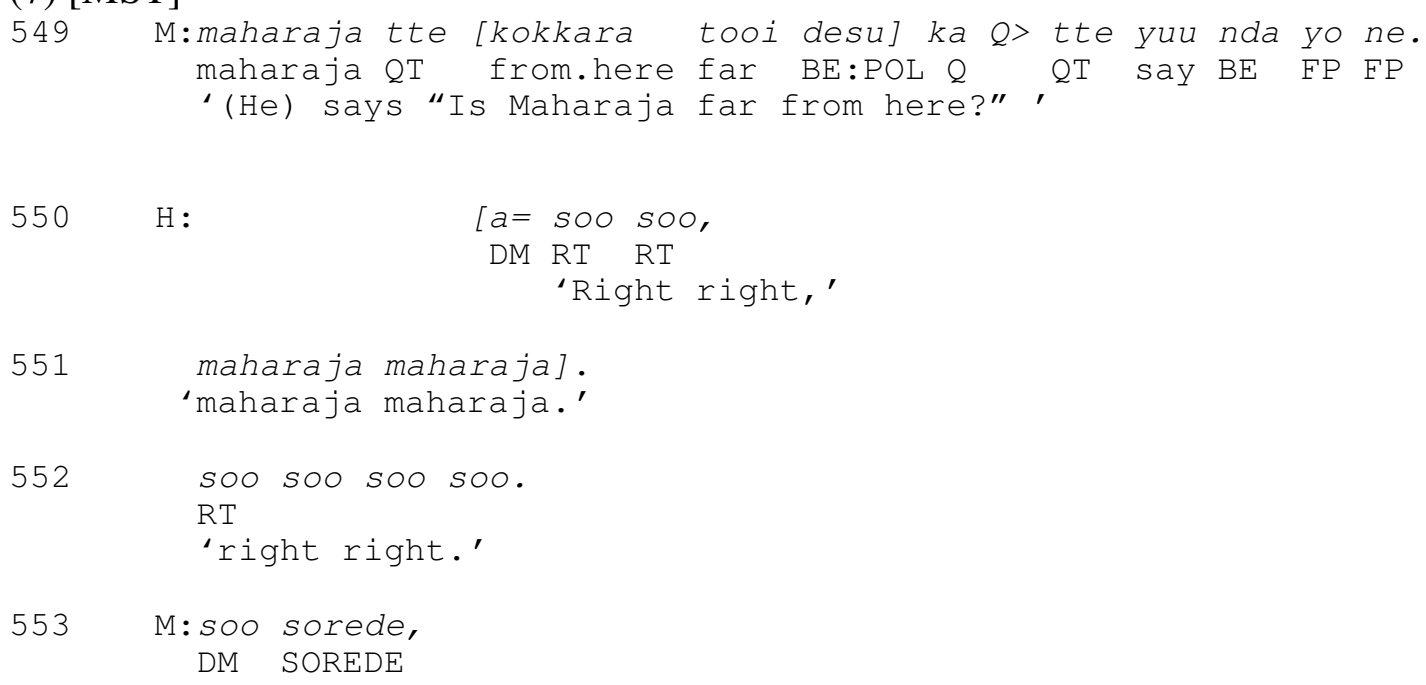

${ }^{9}$ The utterance starting at line 101 is not syntactically completed in that the speaker starts the next utterance unit (not included in the transcript) without expressing the predicate, although it can be easily inferred to be a verb meaning something like 'enter' or 'take', whose subject is undoubtedly 'the father'. 


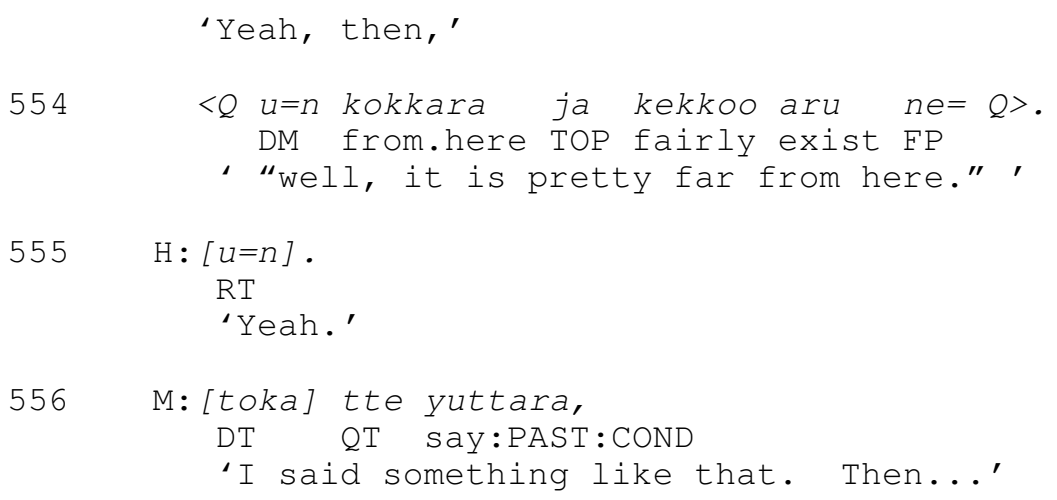

Excerpt (7) takes place when $\mathrm{M}$, prompted by $\mathrm{H}$, who had initiated a story-telling, starts taking over the tellership of the story, which is about a boy who accosted $\mathrm{M}$ and $\mathrm{H}$ at midnight and asked them the location of a discotheque. M quotes the boy in line 549 and her answer to his question in line 554. Note that $\mathrm{M}$ uses sorede in line 553 when the subject of the quotative verb yиu 'say' in these two clauses (lines 549 and 556) is switched to the first person from the third person. ${ }^{10}$

Iwasaki's account for the fact that TARA marks the shift of higher-to-lower information accessibility but not the shift in the reverse direction is that the speaker cannot easily get back to $S$-perspective within the same clausal chain once $s /$ he sets the perspective to the O-perspective.

I would like to suggest an alternative view that takes into consideration the relationship between the interactionality of spoken encounters and the fundamental function of switch reference devices, that is, reference tracking. If we can assume that a device for reference tracking is principally recipient-oriented, the use of such a device should be functionally and interactionally motivated. In face-to-face conversation, the perspective of the first person, that is, the speaker's viewpoint, is most likely to be the default reference point, as shown by the frequent unexpressed first person subjects in the data provided in this and other studies. Thus switching from the first person subject to the third person subject is a deviation from the default reference point, where a confusion is more likely to occur and a resolution for the impending confusion is more urgent, compared to a shift in the opposite direction (i.e. returning to the default after the deviation). Therefore the fact that TARA and soshitara are more consistently associated with subject shift from first person to third person reflects the interactional necessity of systematically and specifically marking this type of subject discontinuity.

\subsection{Tense alternation of attributing verbs}

In telling stories of past events, conversational parties often employ various techniques to make their stories more lively, one of which is to construct dialogues as if the hearers in the present conversation were 'onlookers' to past speech events (Tannen 1989). In Japanese

${ }^{10}$ Also notice that the 'say' verb in line 549 is in the non-past tense, although the speaker is reporting an event in the past. The correlation between person and tense is discussed in the next section. 
the distinction between direct and indirect speech is not clearly made by grammatical markings. Reproducing an utterance just as it would sound in real conversation and attaching the quotative marker tte is enough to indicate that it is reproduced speech. It is often followed by the verb iu 'say' realized in different phonological variations or other verbs expressing cognitive activities such as kiku 'hear/ask.' When reproduced speech is formulated as a dialogue between two alternating speakers, which turn of the dialogue belongs to which of the original speakers is not usually mentioned. That is, subjects of 'say' verbs in constructed dialogue are often unexpressed. Not having to mention each subject for each instance of reproduced speech, the speaker can align the dialogic exchanges next to each other in a sequence, thereby creating rhythmicity and conveying a sense of immediacy, as seen in the excerpt below. Tannen (1989) claims that when speakers represent the words of others in conversation, they are not reporting so much as constructing: "constructing dialogue creates involvement by both its rhythmic, sonorous effect and its internally evaluative effect.' (133) It seems that the possibility of not overtly mentioning the subject in Japanese grammar allows speakers to construct dialogue with less interference of the current speaker's replicating voice, thereby creating more animated and immediate voices of others than when the subject is expressed for each reproduced speech.

Then how do hearers keep track of which turn belongs to whom? ${ }^{11}$ Prosodic features such as distinct voice qualities may help such tracking. Since the reproduced part is presented as it sounded or would have sounded, honorific forms and epistemic particles are used as they were (or would have been) in the original exchanges, and contribute significantly to speaker identification.

Here we observe one device to mark reference shifts in the subjects of attributing verbs, that is, turn-transition in the reproduced dialogue: Past/non-past tense alternation in the verbs of saying seems to be constantly correlated with the alternation between first and third person subject. The following excerpt involve use of attributing verbs that follow this pattern. A is telling a story about a time when she was seated next to young women on a plane on a trip back to Japan. She reproduces the conversation she had with them.

(8) [HAWAI]

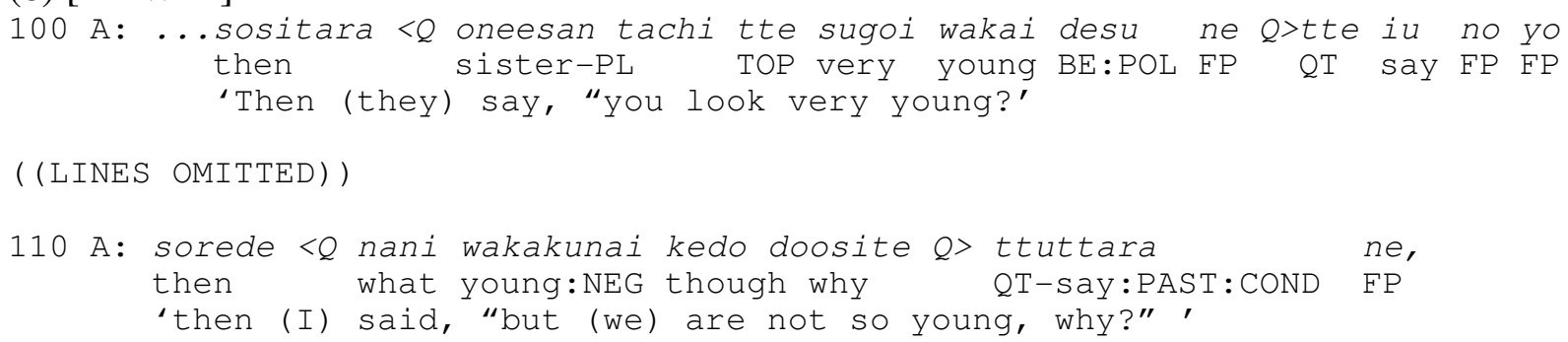

${ }^{11}$ Usually identifying the original speaker of a turn in a constructed (two-party) dialogue can be successfully done without any explicit mentions of the subjects of the 'say' verbs. As we will see later, in reproducing (or constructing) multi-party conversation, the identification of the original speaker of each reproduced turn may be left unclarified, and such unclarity may not be problematized by the other parties to the on-going interaction, as long as speaker identification of each turn is irrelevant to understanding properly the story being reported. In many cases of reproducing multi-party conversation, the reproducing party often turns the reproduced conversation into a dialogue between two characters or groups (often the reproducing party vs. the other) where exact speaker identification does not contribute to the point of the story-telling. 


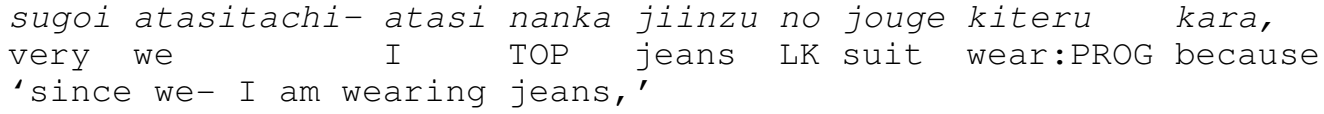

112 B: un un.

113 A: ...tisyatu to.

T-shirt and

'And T-shirt.'

114 B: un.

$115 \mathrm{~A}: \ldots<Q$ naande $Q>$ tte ittara,

why QT Say:PAST:COND

'(I) said, "why",

116

(H) <Q karada no sen mo kuzurete naishi Q> body LK line too out.of. shape NEG:CONT

" "your body line is in shape, too." '

((LINES OMITTED: SPEAKER A TALKS ABOUT HOW SHE WAS DRESSED))

123 A: ..soositara ne <Q wakai si Q> the iu kara,

then FP young and QT say because

"then, since (they) say, "(you) are young," '

$124<Q$ tonde mo nai konna okkina kodomo ga iru no yo Q> ttara, no.way this big child NOM exist FP FP

'(I) said, "No way, (I) have a kid this big," ,

$\ldots<Q$ hee jaa,

DM then

'(they) are surprised (saying) "oh then,'

126 ...ikutu de kodomo san undandesu ka Q> tte odoroku wake yo what.age at child HON bear:PAST:POL Q QT surprised DM FP "how old were you when you had your child?" '

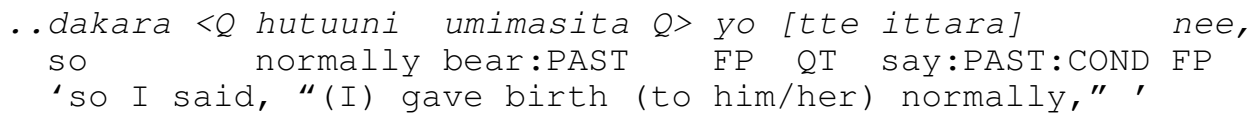

128 B :

[un hutsumi],

RT normally

right, normally,

$129 \mathrm{~A}$ : <Q mada sanjuu dai no zenpan ka to omotta nda Q> tte yuu no still thirties LK early Q QT think:PAST NM:BE QT say FP

"then (they) say, (we) thought (you) were in (your) early thirties."'

130 B: $u u=n$.

$\mathrm{RT}$

I see. 


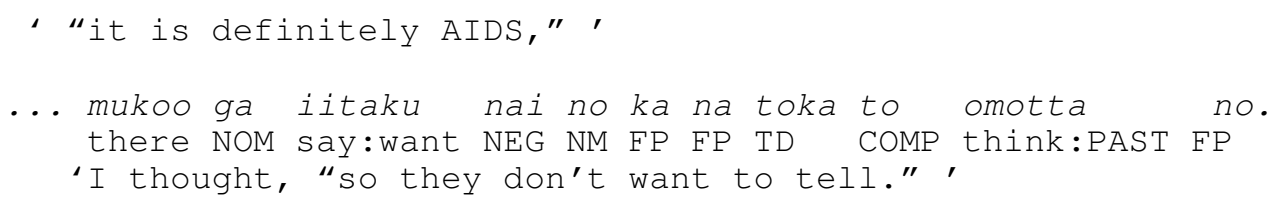

In Excerpt (9) $\mathrm{R}$ is talking about the time when she suffered from polyps, the cause for which was not known. As it becomes explicit in line 215, the doctor is the referent of the subject of the 'say' verb in non-past tense (уии in line 214). The cognitive verb omou 'think' in line 218, whose subject is the speaker, is produced in past tense, following the pattern.

(10) $[\mathrm{MH}]$

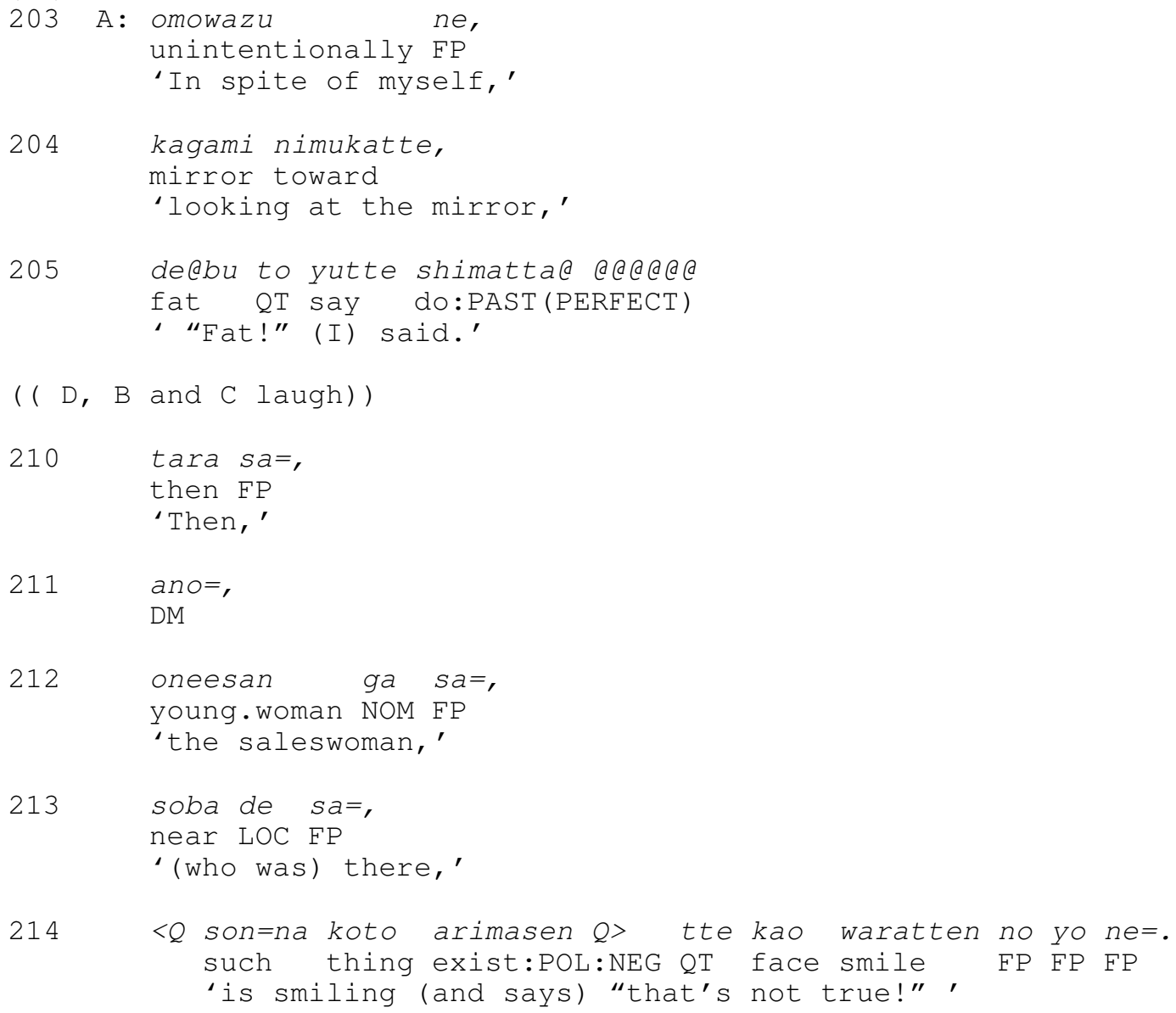

In line 205 in Excerpt (10), again, the 'say' verb whose subject is first person is in the past (perfect) tense, while the verb warau 'smile' describing the saleswoman's action is in the non-past (progressive) tense.

Although detailed discussion of why first person is associated with past tense and third person with non-past tense as they are in the present data is beyond the scope of this paper, the instances given here clearly follow the pattern of S-perspective sentences 
occurring with past tense and O-perspective sentences ${ }^{13}$ occurring with non-past sentence reported in Iwasaki (1993). In fact, Iwasaki observed the pattern in which first person subjects often occur with past forms while third person subjects and inanimate subjects tend to occur with non-past forms in his data of first person narratives. He concluded that this PAST-NONPAST distribution can be explained by his information accessibility hypothesis:

Situations which the speaker can access more directly are coded by clauses with higher transitivity features. Situations which the speaker accesses less directly are coded by clauses with lower transitivity features. (22)

Sentences with a first person subject is on the higher side of the information accessibility scale, accordingly associated with high transitivity features, one of which is claimed to be past tense, whereas sentences with a third person subject or an inanimate subject is on the lower side, associated with low transitive features which include non-past tense (Hopper and Thompson 1980).

Iwasaki's information accessibility hypothesis provides us with insights into the ways in which certain linguistic forms marking the cognitive and pragmatic feature, the speaker's perspective, are employed to resolve reference identification of unexpressed elements. The excerpts analyzed in this section further present this phenomenon as one example of 'grammar' shaped by discourse/interactional motivations, which in turn serves as a resource conversational parties can utilize to interpret and indicate who is the unexpressed speaker of reproduced speech, thereby co-constructing a world of reported discourse.

\subsection{Tense alternation indicating generic/specific interpretation}

Past/non-past tense alternation appears to be associated with another distinction relevant to interpretation of the subject referent. It is not uncommon for the same predicate to occur in sequence and have different implicit subjects, one referring to a category or a nonidentifiable member of a category, the other referring to a specific entity within the category. In the following excerpt, this kind of subtle switch reference is found. Interestingly, it correlates with tense alternation of the verb mirareru 'be seen.'

(11) [HAWAI]

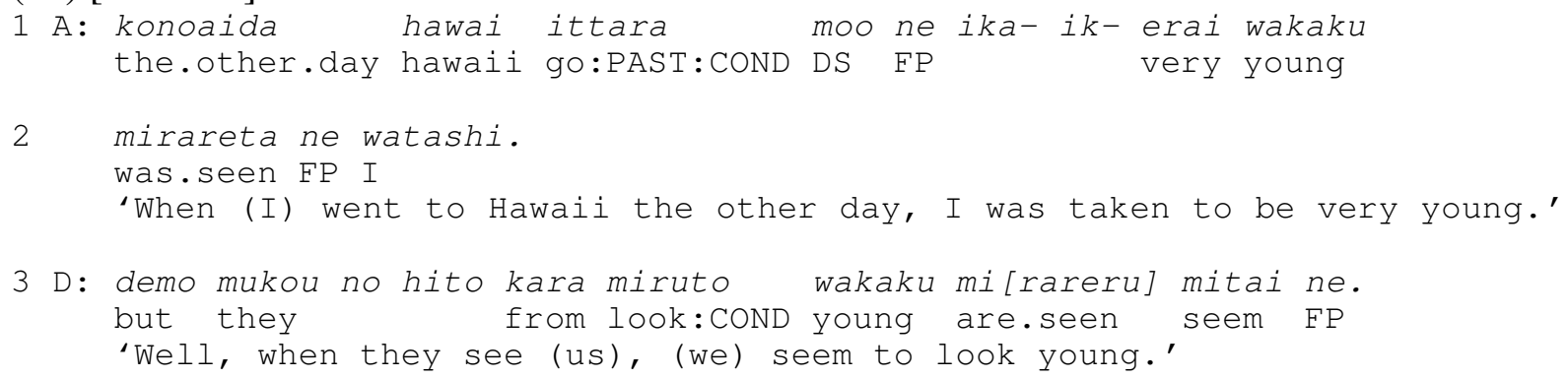

${ }^{13}$ See 3.2. for a brief explanation of S-perspective and O-perspective. 


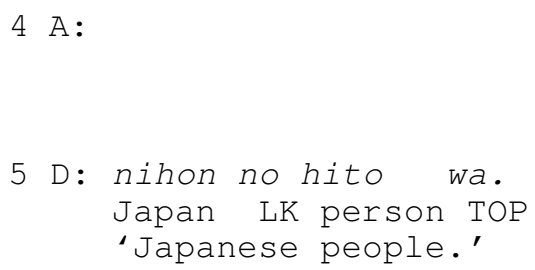

In lines 1 and 2, $\mathrm{A}$ initiates a story about her trip to Hawaii, where she was taken to be young. She uses the past passive form of the verb miru, mirareta 'was seen.' Rather than prompting A to continue her story, D introduces the common view that Japanese are taken to be young by Westerners. Clearly, D's statement is about Japanese people in general, as shown by the post-predicate subject nihon no hito wa 'Japanese people TOP' in line 5. D uses the same verb as A but in the present passive form, mirareru. A agrees with D by repeating D's statement, adding an upgrading term sugoi 'very' (line 4). The recycled verb in the non-past tense in A's second turn in line 4 indicates that she is acknowledging the common view invoked by $\mathrm{D}$, while A's action would have been seen as supporting the view by emphasizing her own personal experience if she had used the past tense form. That is, use of the past tense here would be seen as referring back to her prior turn introducing her story and therefore the subject of the verb would be the speaker again, not Japanese people in general. Thus this instance again shows that even though subjects are not explicitly expressed, the hearers are furnished with resources to designate a referent for an unexpressed subject.

Such settings as story-telling in conversation involve multiply layered levels of discourse. Which level of the organization is invoked is indicated in various ways by various linguistic (and by non-linguistic) resources. These discourse-framing features necessarily constrain the range of possible referents for unexpressed relevant participants in the described action/state. In the following sections we turn to some factors constraining possible interpretations of unexpressed referents at higher organizational levels of discourse.

\subsection{Framing described situations}

In the instances analyzed above, the referents of the unexpressed subjects are, except for the cases of generic referents, conversational parties or are already explicitly mentioned in the prior talk, which contributes significantly to narrowing down the range of possible referents for a particular participant projected by a predicate occurring in the subsequent talk. However, in some cases a third person participant which has not been previously mentioned can be inferred to be the referent of an implicit subject. One typical way in which such an inference takes place is when the situation being described has been established by mentioning the time and place of the event in adverbial phrases. Let us look at Excerpt (12) below, which is from the same conversation with five female participants as Excerpts (8) and (11) are taken from. 
(12) [HAWAI]

136 D: demo hora kiru mono datoka,

but DM wear NM and.the.like

'But, see, what to wear,'

137 seishintekini [mo] $n[e=]$,

mentally too FP

'(we change) mentally (according to what to wear),'

138 B :

$$
\begin{array}{ll}
\text { [un] } & \text { [un]. } \\
\text { RT } & \text { RT } \\
\text { 'Yeah, right.' }
\end{array}
$$

$139 \mathrm{~A}:[u=n]$

$\mathrm{RT}$

'Right.'

140 B: $[u=n]$

$\mathrm{RT}$

'Right.'

141 D: ningen tte hora, [XX]

human being TOP DM

'(You know), people,'

142 B:

[datte],

because

'Because,

143 B: ..zenzen chigau,

at.all different

'(people) look very different.'

hukeikai toka,
PTA

145 ...de ne,

at FP

'at a PTA meeting or something,'

146 A : $u=n$.

147 B: soo,

$\mathrm{RT}$

'yeah,'

148 miruto,

see: COND

'when (I) see (them),'

149 zenzen chigau desu yo=.

at.all different BE:POL FP

'(they) look very different.'

150 A: ..un onnasi yoona nendai da mon [ne]. 


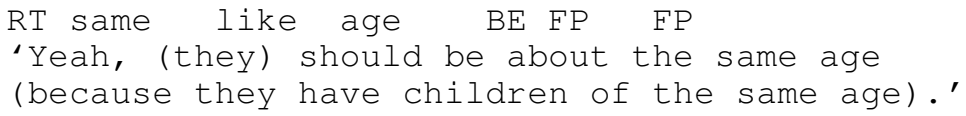

The parties have been talking about 'looking young' or 'being taken to be young,' a topic initiated by A's story about her trip to Hawaii. In line 141, by explicitly referring to 'people (in general)' D clarifies that she is about to make some general comment about people based on what was already produced in lines 136 and 137 . D, however, cuts herself short as soon as B initiates her turn in overlap with D in line 142. It is B who restarts after the overlap has been resolved (line 143). It is ambiguous who/what is the subject of the predicate zenzen chigau 'are totally different' at the point it is produced except that the turn is somehow informed by D's preceding talk. It becomes clear that her second zenzen chigau in line 149 is no longer about 'people in general' but about something specific, as the use of the particle yo indicates: Basically yo is used when the speaker shows that she assumes that she is more knowledgeable of the matter in question than the hearer (Cook (1992), Kamio (1986), Maynard (1989, 1993), Suzuki (1992)). Thus the referent of the unexpressed subject is something (someone) that the speaker has more access to than the hearers. The only possible interpretation of the referent of the unexpressed subject in this turn is people who are at PTA meetings, namely, parents with children of the same age. B never explicitly mentions such a group of people during the segment, although the adverbial phrase in lines 144 and 145 providing a frame of the situation being talked about constrains the possible participants that can be relevantly related to the predicate in line 149. Note that A's comment in the next turn in line 150 (about being about the same age) shows that she understands what the subject is assumed to be in B's preceding turn; not only does she build her own utterance on this understanding, but she also assumes that the hearers understand that the unexpressed subject in her turn is carried over from B's preceding turn. This shows that participants can utilize not only morpho-syntactic devices, as discussed in the previous sections, but also expressions that frame the situation being described in order to interpret or indicate an unexpressed referent.

\subsection{Sequential structures embedded in reproduced conversation}

In the preceding section we have observed that the frame set up at the initiation of a particular sequence of talk constrains the possible participants in the event being described. In this section, we will look at cases in which such framing provides the organization of sequence structures of the reproduced speech (e.g. turn-taking among the original speakers, and turn-allocation).

In the following excerpt $\mathrm{K}$ tells a story about someone who had misconstrued some Chinese characters on a menu at a noodle restaurant. K reproduces the dialogue which supposedly took place when the friend and two other friends ordered their noodles. For the sake of readability, a free English translation of the whole segment is provided below the transcript.

(13) [RAAMEN]

$1 \quad \mathrm{~K}$ : mae ne,

$$
\begin{aligned}
& \text { mae ne, } \\
& \text { before FP }
\end{aligned}
$$


Tomoyo Takagi

2

mae $n e=$, before FP

3

... ano,

$\mathrm{DM}$

. raamen $o=$, noodle ACC

5

7

otomodachi ga=, friends NOM

.. $a n o=$,

$\mathrm{DM}$

sannin de tabeni ittan datte.

threesome to.eat go:PAST:NM BE:QT

8

$\mathrm{R}$ : un.

$\mathrm{RT}$

9

$\mathrm{K}: \mathrm{de}$,

then

10

11

nanni shimasu ka toka,

what do:POL Q TD

zuibun maeni yutteta $<X$ toka $X>$ itte

very early say:PAST TD say:CONT

12 K: . < Atashi shio= Q>

I salt

13

toka itte=.

TD say: CONT

14

... de,

then

15

$<Q$ atashi shooyu $=Q>$.
I

16

toka itte,

TD say:CONT

17

$<Q$ e ja=,

well then

18

atashi wa= Q>,

I TOP

19

toka itte,

TD say:CONT

20

$<Q$ ajimashi $Q>$. 


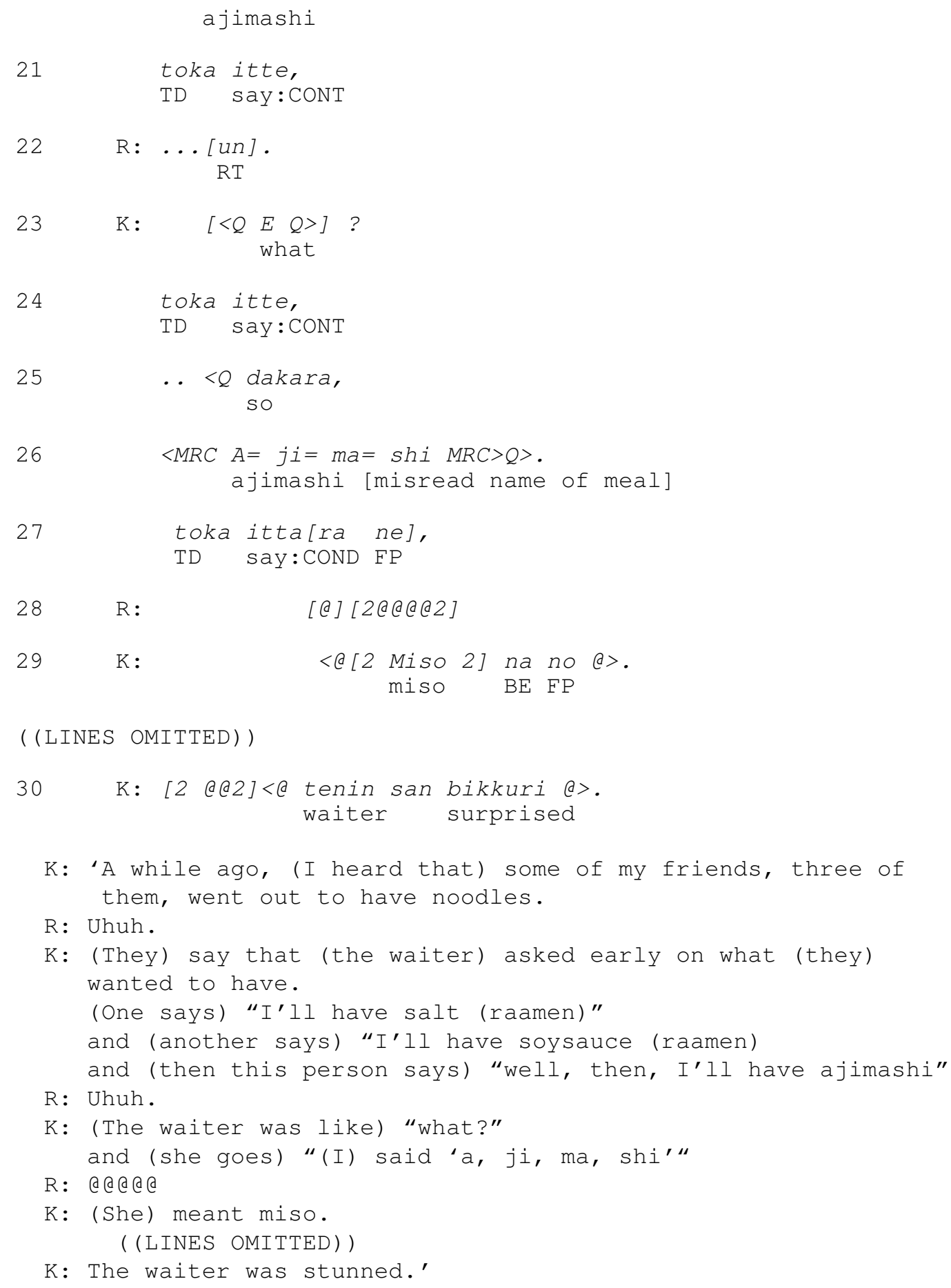

As in the examples in 3.3., the subject of the reporting verb iu 'say' is not expressed in this reproduced conversation either. ${ }^{14}$ Which utterance is attributed to whom is disambiguated

${ }^{14}$ In this and the following excerpts, most of the 'say' verb are in the continuing (non-finite) form tte. Although it is glossed as CONT and translated as non-past tense in the transcripts, past/non-past tense 
sufficiently for the purposes at hand in the on-going activity, that is, telling a funny story. Which of the three customers ordered which kind of noodle is not relevant except that the third one misconstrued and accordingly pronounced the Chinese letters for the noodle she thought she was ordering (lines 20, 25 and 26). In this frame of ordering meals, it is predictable that the reported conversation is between those who order and the one who takes orders. Thus the question in line 10 can be appropriately interpreted as the waiter's utterance. Similarly, the interjection $e$ ? in line 23, which usually expresses puzzlement or surprise, can be attributed to the waiter, who is responding to the order that was pronounced in an unexpected way. Note that the first mention of the waiter occurs in line 30, after the punch line is provided and appreciated by the hearers. This retrospectively confirms the attribution of the utterances in lines 10 and 23 to the waiter. Thus the frame of the situation in which 'three friends went out to eat noodles' established at the introduction of the story evokes the hearers' schematic knowledge of 'ordering meals at a restaurant,' which then constrains who the possible parties are and how the participation framework for the conversation occurring in such a social setting is likely to be organized.

Excerpt (14) illustrates a more generalizable feature of the conversational parties' knowledge of how conversation is organized. In the talk prior to the excerpt, $\mathrm{M}$ had been telling about a group of high school students who approached her and her friend on the street. From their distinct accents she recognized that they were from a certain area in Japan and playfully pretended to speak the same dialect, imitating their accents. The excerpt starts with the high school students' reaction to the way M spoke, namely, asking whether she is from the same area as they are.

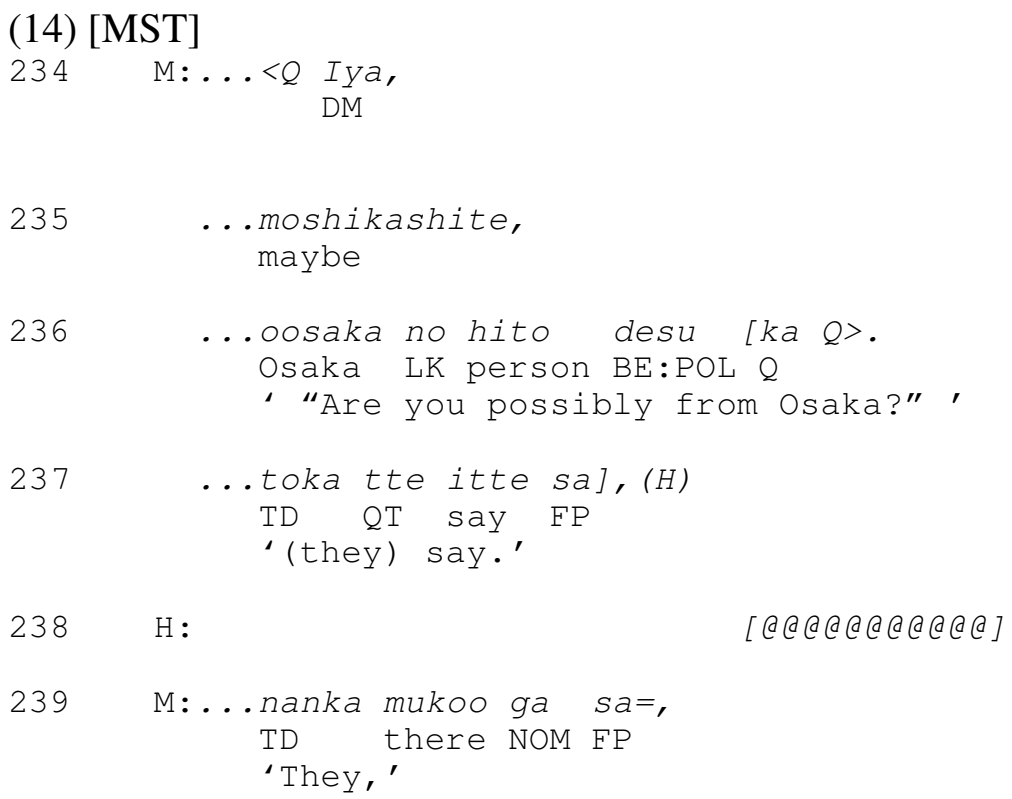

is not differentiated in any morpho-syntactic way. Thus the tense-shift pattern we have seen in 3.3 . is not necessarily applicable to all the instances of the 'say' verb here. 
$m=$ me ga kagayaichatte sa, eye NOM brightened:CONT FP

'with their eyes brightened,'

241

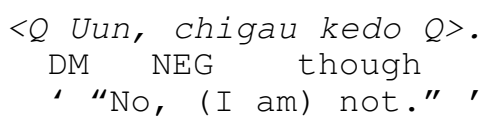

242

. [< toka itte e>.

TD say

' ( I ) said.'

In lines 239 and $240 \mathrm{M}$ describes how they looked when they heard her speaking with the same accent as theirs. Me ga kagayaichatte (line 240) is an idiomatic phrase literally meaning 'eyes are brightening,' which can be analyzed as an unitary predicate of the subject mukoo ga 'they (lit. there, referring to a third party; 'he high school students' in this case).' The continuing form -tte at the end of the idiomatic phrase as well as its continuing pitch indicate that the clause is not complete at the end of the utterance in line 240, which arguably projects the same subject as the one in line 239 for the upcoming portion. However, M's next utterance in line 241 is so produced as to be heard as an answer to the question asked by the foursome in the story. Note also that $M$ suddenly switches to her own accent, enacting how she tricked the high school students by mimicking their accents. Therefore the unexpressed subject of the 'say' verb in line 242 is inferred to be the speaker herself, not the high school students. This is no less orderly than the alternative case in which the subject would have remained the same, in terms of how usual conversations are organized: Questions are regularly followed by answers from the recipient of the question. ${ }^{15}$ This can be seen as an instance in which local linguistic cues pointing to one possible interpretation of the unexpressed subject referent is overridden by more general conversational parties' knowledge of sequential structures in conversation.

\section{Invoking on-going interactional conditions}

\subsection{Explicitly invoking shared knowledge}

As they proceed with sequences of talk, conversational parties constantly monitor each other's accessibility to the information relevant to the matter in question in on-going interaction. For example, the Japanese particles yo and ne, very frequently used in conversation, are sensitive to speakers' recognition (or display of recognition) of such shared knowledge, as described in a number of studies (e.g. Cook 1992; Kamio 1986; Maynard 1989, 1993; and Suzuki 1992). Occasionally, parties may be explicitly engaged in work that precludes an imminent problem due to the discrepancy between the speaker's knowledge and that of the hearers. In the following excerpt, $\mathrm{M}$, who has been a story-teller,

${ }^{15}$ This does not mean questions are always followed by answers. But it has been shown that conversational parties orient to such a recurrent pattern in the course of producing their own turns and interpreting others' turns. For detailed discussions of adjacency pairs such as QuestionAnswer, see Schegloff and Sacks (1973) and Heritage (1984). 
evokes the shared knowledge of the place where the incident being told took place, by using the discourse marker hora (line 153) and the tag janai (line 156). The token hora is often used to draw the hearer's attention, or here more specifically, to encourage the hearer to recollect something, and the tag indicates the speaker's assumption that the hearer is knowledgeable with respect to the matter in question, although the knowledge may not have been activated.

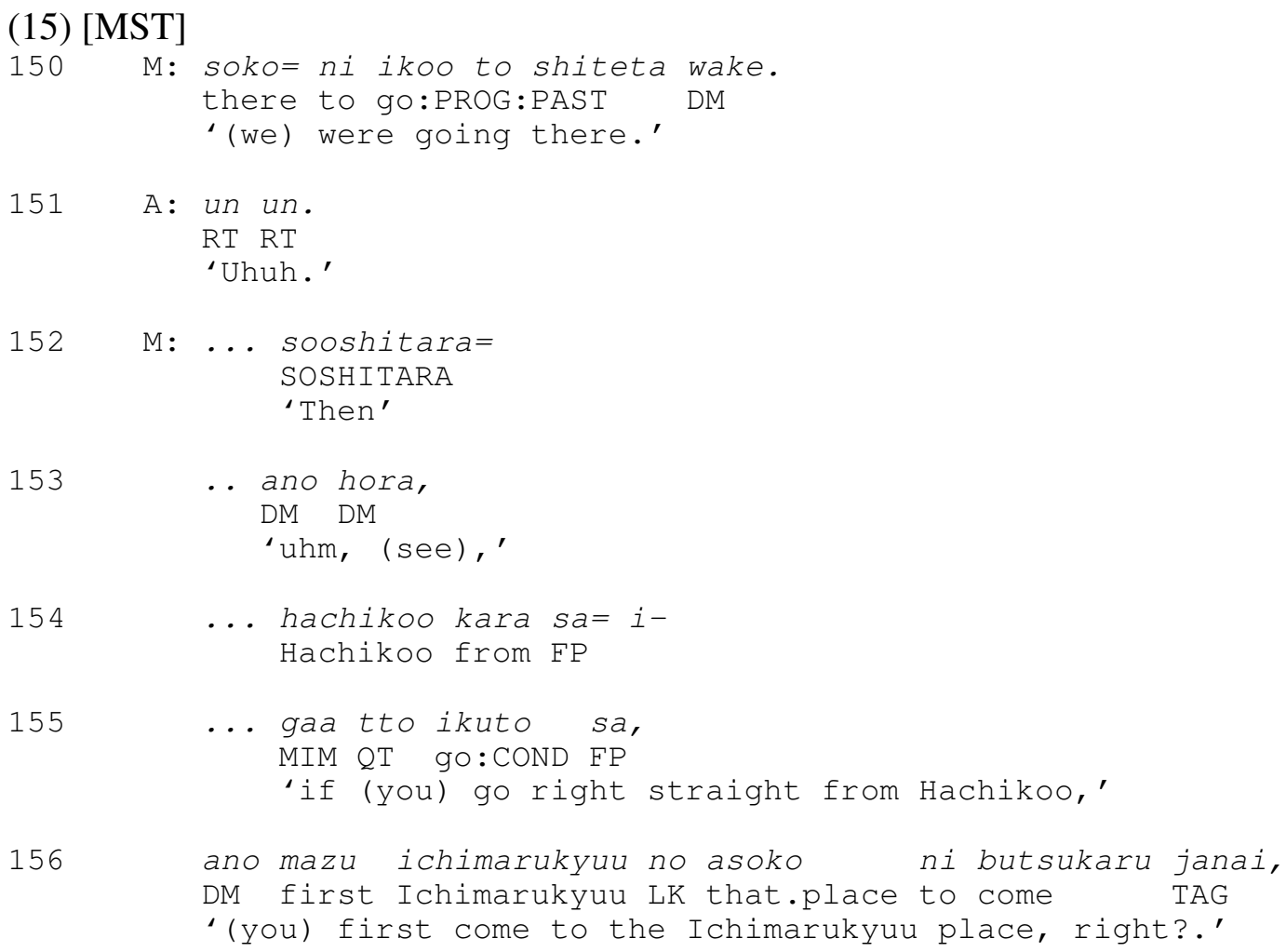

M recognizably shifts her participation status from a teller to an interactant who is concerned with the immediate interactional task of establishing the shared knowledge about a place relevant to the story. The unexpressed subjects in lines 155 and 156 are profiled in such a frame: The way in which the shared recognition of a place is established calls for generic interpretation of the referents of the subjects, namely, 'you/we (generic)' - whoever goes straight ahead from Hachiko (a famous statue in front of a big station) comes to the Ichimarukyuu place. ${ }^{16}$ Thus the reference switch from the speaker and her friend as characters in the story (line 150) to a generic person (lines 155 and 156) is achieved through claiming certain knowledge to be shared by the hearers as co-participating parties in the ongoing interaction. ${ }^{17}$

${ }^{16}$ The tense alternation from the past in line 150 to the non-past in line 155 also contributes to marking the specific/generic referent shift (see section 3.4).

${ }^{17}$ Also note the use of soshitara in line 152. This use of soshitara is consistent with the account for the restriction in the use of soshitara discussed in Section 3.2. in that the reference shift here is from S-perspective to O-perspective. 
unexpressed participant in the event/state represented by the predicate should be distinguished from their process of interpreting what participants the predicate projects as possibly relevant in that particular context. This claim is supported by phenomena in which hearers appropriately interpret what participants are projected and made relevant by the use of a predicate in a particular context, although they find themselves unable to identify the referent of the projected participant precisely enough to understand the current utterance appropriately. Such phenomena constitute reference negotiation situations in which the hearer seeks more information about what is intended to be the referent of the unexpressed participant.

In Excerpt (17) R has been talking about the time when her father was operated on for stomach cancer. Below the transcript is a free translation.

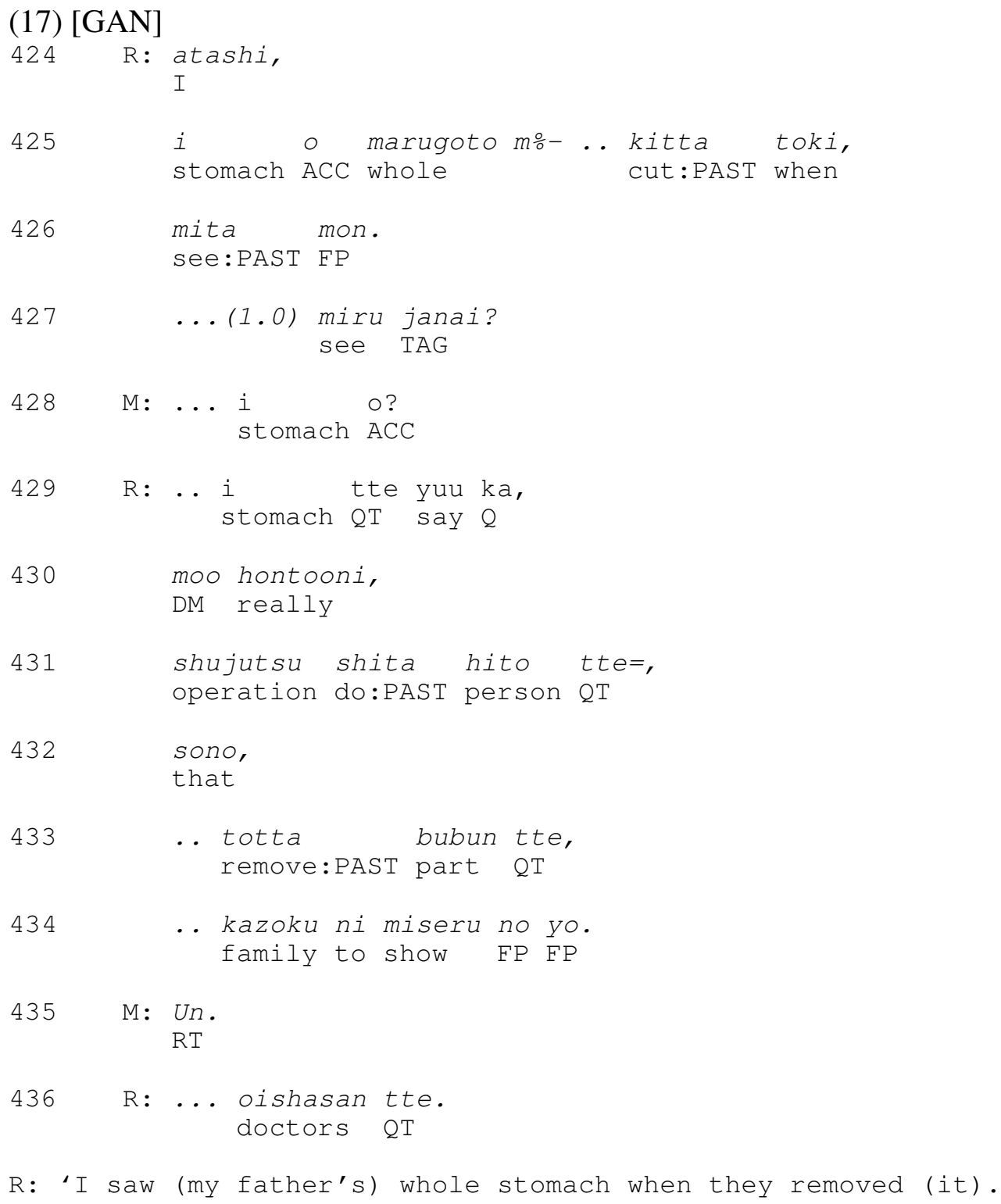




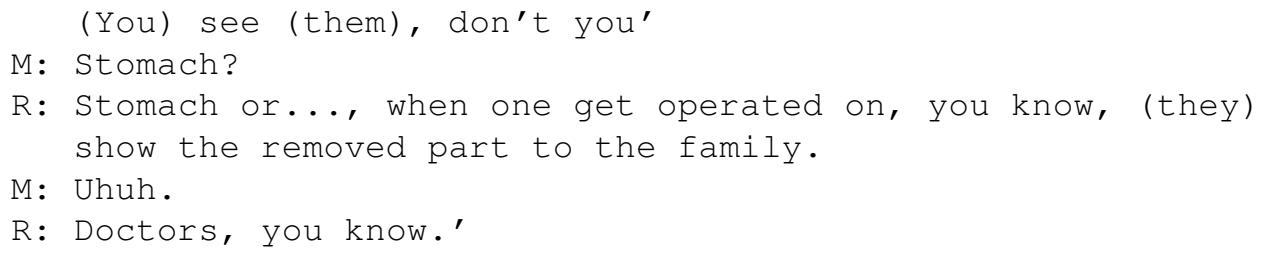

In lines 424 to $426 \mathrm{R}$ says that she saw her father's removed stomach. In line 427 she utters the verb miru 'see' in the non-past tense followed by the tag-question form janai. This is interpretable as a confirmation of the shared experience or general knowledge about 'seeing' something after an operation. It is apparent that the subject is shifted from a specific referent, that is, speaker R, to a general category of 'people' or 'we' including hearer M. ${ }^{19}$ This appears to cause a confusion on M's part. Although what is seen, that is, the object of the verb 'see' is already invoked in the prior context and projected as well for this particular occurrence of the same verb, identifying the referent of the object is not so straightforward - it can no longer be 'R's father's stomach,' nor even 'somebody's stomach' because stomach is not necessarily the body part that gets removed when a person undergoes an operation. Thus knowing that the participant 'what is seen' is implicit but not knowing what exactly the referent is, $M$ requests clarification in line 428 by offering a candidate referent. In response to M's request for clarification, $\mathrm{R}$ explains that doctors usually show whatever the removed part to the patient's family. This instance shows that when multiple resources employed by parties to identify referents anomalously co-occur, they can even be sources of confusion for hearers who are attempting to identify the referents. However, importantly, hearers can still infer possible participants for which referents are to be clarified through the work of reference negotiation.

\section{Conclusion}

In this study I explored ways in which conversational parties employ differing resources in the immediate context to infer the referents of unexpressed participants in order to achieve appropriate understanding of each other's utterances. It has been shown that diverse, multilayered factors conspire to help hearers single out the most likely referent for a particular implicit participant. We have also seen a case in which there is a discrepancy among parties in what referent is inferred/intended for the same unexpressed argument. Importantly, such a reference negotiation situation should be seen as further evidence, but not counter-evidence, for the language users' ability to relate their knowledge of lexical properties of verbs (including their argument structures) to available contextual resources in the most relevant way.

Each of the instances discussed in this paper remains to be further investigated and tested based on more extensive and detailed observation of expanded data base. This study also leaves room for further examination of how the various resources described here balance out against each other, or which takes precedence over the others if more than one is at work in a given context.

I hope this study at least has shown that what has been described as 'zero anaphora'

${ }^{19}$ See 3.4. for discussion of non-past tense associated with the generic interpretation. 
and often analyzed as a phenomenon based on a limited set of syntactic principles in fact supports the view that grammar can come to existence only through the medium of discourse (Clancy 1997). That is, if Japanese speakers knows what is unexpressed and what can be unexpressed (or even what should be unexpressed to produce natural Japanese utterances) in interacting with each other in their everyday life, such knowledge should be regarded as part of 'grammar,' and such grammar is significantly shaped by discourseinteractional motivations. This study has shown how discourse/contextual as well as morpho-syntactic resources can be organized into the means of identifying unexpressed referents. The very fact that the use of these resources has the describable organization suggests that the discourse/interaction-mediated grammar can be analytically captured by exploring linguistic phenomena as they occur in their home environment, that is, interactions in real-life communicative settings.

\section{References}

Chafe, Wallace (ed.) (1980) The pear stories. Norwood, New Jersey: Ablex.

Clancy, Patricia M. (1996a) Discourse motivations of referential choice in Korean acquisition. In Japanese/Korean Linguistics V.

Clancy, Patricia M. (1996b) Referential strategies and the co-construction of argument structure in Korean acquisition. In Barbara Fox (ed.), Studies in anaphora. Amsterdam/Philadelphia: John Benjamins, pp. 33-68.

Clancy, Patricia M. (1997) Lecture. Seminar in psychology. Winter Quarter, The University of California, Santa Barbara.

Clancy, Patricia M. (in preparation) A discourse-functional approach to argument structure: A developmental study of Korean.

Cook, Haruko M. (1992) Meaning of non-referential indexes: A case study of the Japanese sentencefinal particle ne. Text 12.4: 507-539.

Du Bois, John W. (1980) Beyond definiteness: The trace of identity in discourse. In Wallace Chafe (ed.), The pear stories. Norwood, New Jersey: Ablex, pp. 9-50.

Du Bois, John W. (1997) Lecture. Advanced discourse course. Winter Quarter, The University of California, Santa Barbara.

Du Bois, John W., Stephan Schuetze-Coburn, Susanna Cumming, and Danae Paolino (1993) Outline of discourse transcription. In Jane A. Edward and Martin D. Lambpert (eds.), Talking data: Transcription and coding in discourse research.

Du Bois, John W., and Sandra A. Thompson (1991) Dimensions of a theory of information flow. ms.

Goldberg, Adele (1995) Constructions. Chicago: The University of Chicago Press.

Heritage, John (1984) Garfinkel and ethnomethodology. Cambridge: Polity Press.

Hopper, Paul, and Sandra Thompson (1980) Transitivity in grammar and discourse. Language 56.2: 251299. 
Iwasaki, Shoichi (1993) Subjectivity in grammar and discourse: Theoretical considerations and a case study of Japanese spoken discourse. Amsterdam/Philadelphia: John Benjamins.

Kamio, Akio (1990) Joohoo no nawabari riron (A theory of territory of information). Tokyo: Taishuukan.

Kuno, Susumu (1987) Empathy perspective. In Functional syntax: Anaphora, discourse and empathy. Chicago: University of Chicago Press.

Lee, Won-Pyo (1989) Referential choice in Korean discourse: Cognitive and social perspective. Ph.D. dissertation, University of Southern California.

Levinson, Stephen C. (1983) Pragmatics. Cambridge: Cambridge University Press.

Maynard, Senko K. (1989) Japanese conversation: Self-contextualization through structure and interactional management. Norwood, New Jersey: Ablex.

Maynard, Senko K. (1993) Discourse modality. Amsterdam/Philadelphia: John Benjamins.

Myhill, John, and Junko Hibiya (1988) The discourse function of clause chaining. In John Haiman, and Sandra Thompson (eds.), Clause combining in grammar and discourse. Amsterdam/Philadelphia: John Benjamins, pp. 71-100.

Okamoto, Shigeko (1985) Ellipsis in Japanese discourse. Ph.D. dissertation, The University of California, Berkeley.

Ono, Tsuyoshi, and Sandra A. Thompson (1997) Deconstructing 'zero anaphora' in Japanese. Berkeley Linguistics Society 23.

Shibatani, Masayoshi (1990) The languages of Japan. Cambridge: Cambridge University Press.

Suzuki, Ryoko (1990) The role of particles in Japanese gossip. Berkeley Linguistics Society 12: 315-324.

Tannen, Deborah (1989) Talking voices: Repetition, dialogue, and imagery in conversational discourse. New York: Cambridge.

\section{Appendix}

Transcription Conventions used in the excerpts are based on Du Bois et al. (1993).

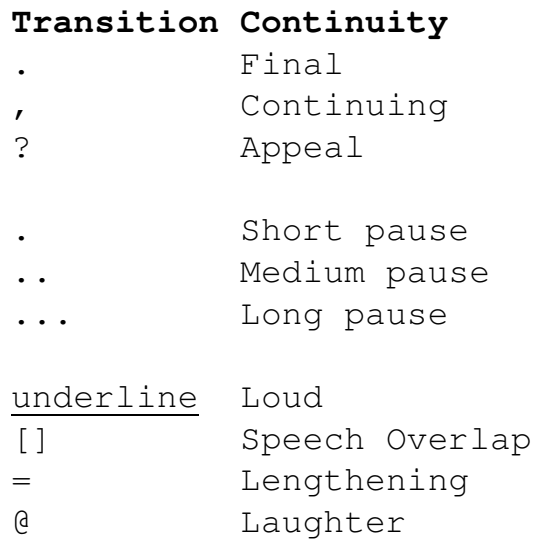


Tomoyo Takagi

$\begin{array}{ll}(\mathrm{H}) & \text { Inhalation } \\ (\mathrm{HX}) & \text { Exhalation } \\ <\mathrm{Q}> & \text { Laugh quality } \\ <\mathrm{Q} \text { Q }> & \text { Quotation quality } \\ <\text { MRC MRC }> & \text { Marcato speech } \\ <\mathrm{X} X & \text { Uncertain hearing } \\ \mathrm{X} & \text { Indecipherable syllable } \\ ((\mathrm{N})) & \text { Researcher's comment }\end{array}$

\section{Abbreviations in glosses}

$\begin{array}{ll}\text { ACC } & \text { accusative marker } \\ \text { BE } & \text { copulative verb } \\ \text { COMP } & \text { complementizer } \\ \text { CON } & \text { concessive } \\ \text { COND } & \text { conditional } \\ \text { CONT } & \text { continuing form } \\ \text { DM } & \text { discourse marker } \\ \text { FP } & \text { final particle } \\ \text { LK } & \text { linker } \\ \text { MIM } & \text { mimetic } \\ \text { NEG } & \text { negative } \\ \text { NOM } & \text { nominative marker } \\ \text { NM } & \text { nominalizer } \\ \text { QT } & \text { quotative marker } \\ \text { Q } & \text { question particle } \\ \text { RT } & \text { response token } \\ \text { TD } & \text { tone downer }\end{array}$

